\title{
Exploring sense of community within an online health care context
}

Dr Tauheed Ramjaun

\section{Introduction}

This study explores the dimensions of sense of community (SOC) within an online health care forum managed by a charitable organisation in the UK which supports people living with arthritis. The main tenets of the concept of SOC can be traced back to the early studies of rural communities (Glynn 1981) but over the past decade, this notion has been acknowledged as a key construct within so-called online communities (Blanchard 2008). In this paper, the concept of SOC as theorised by McMillan and Chavis (1986) is used as a conceptual lens to better understand community dynamics within this particular health care context in order to help community managers in their tasks of sustaining strong online communities and encourage positive relationships with different online stakeholders.

Drawing upon several decades of research in the field of group cohesiveness, McMillan and Chavis (1986) defined SOC as "a feeling that members have of belonging, a feeling that members matter to one another and to the group, and a shared faith that members' needs will be met through their commitment to be together" (McMillan and Chavis 1986, 9). They argued that SOC consisted of four main elements which are summarised below.

Table 1. Sense of community elements

\begin{tabular}{|l|l|}
\hline Elements & Definition \\
\hline Membership & $\begin{array}{l}\text { The feeling of belonging or of sharing a sense of personal } \\
\text { relatedness }\end{array}$ \\
\hline Influence & A sense of mattering, of making a difference to the a group and \\
\hline
\end{tabular}




\begin{tabular}{|l|l|}
\hline $\begin{array}{l}\text { Integration and } \\
\text { fulfilment of needs }\end{array}$ & $\begin{array}{l}\text { The feeling that members' needs will be met by resources } \\
\text { received through their membership in the group }\end{array}$ \\
\hline $\begin{array}{l}\text { Shared emotional } \\
\text { connection }\end{array}$ & $\begin{array}{l}\text { The commitment and belief that members have shared and will } \\
\text { share history, common places, time together and similar } \\
\text { experiences }\end{array}$ \\
\hline
\end{tabular}

Adapted from McMillan and Chavis (1986)

This conceptualisation of SOC has been applied and researched more recently in the online context (e.g. Koh et al. 2003, Blanchard and Markus 2004, Blanchard 2007, Abfalter 2012). Blanchard and Markus (2004) first explored dimensions of SOC within a newsgroup of people interested in multiple sports event. They concluded after a naturalistic inquiry involving participant observation and member interviews that dimensions of sense of community were present but they differed from that manifested within physical communities. Subsequent studies attempted to use quantitative measures to test existing scales of sense of community originating from studies within offline communities (Blanchard 2007). Blanchard $(2007,827)$ introduced the construct of sense of virtual community (SOVC) as "members' feelings of membership, identity, belonging, and attachment to a group that interacts primarily through electronic communication." The reason for a different construct was because her study tended to indicate that sense of community manifested differently within online settings. However, she reinforced the fact that sense of virtual community is the key feature that "distinguishes virtual communities from mere virtual groups" (Blanchard 2008, 2107).

So far, dimensions of SOVC have been tested and refined using mostly quantitative scales (Blanchard 2008, Obst and Stafurik 2010, Abfalter et al. 2012). One of the most recent quantitative studies by Abfalter et al. (2012) confirmed that the four dimensions of sense of community as identified by McMillan and Chavis (1986) by using an updated version of a sense of community index proposed by (Chavis, Lee and Acosta, 2008) contradicting the 
previous works by Blanchard (2008). Therefore it can be argued that research in the area of sense of community within online groups is still at its infancy and there is a need to explore this construct in more depth with more qualitative approaches in different types of platforms (Abfalter et al. 2012) as well as in specific sectors where such communities are thriving such as online health care communities.

Online health communities have been growing in importance over the past decade with the potential of providing various benefits for the different stakeholders involved within that sector (Johnson and Ambrose 2006). While there has been a body of work that has "investigated the dynamics of virtual communities across a range of different conditions" (Kirk and Milnes 2016, 310), there is a felt need of better understanding and measuring the elements of SOC within such heath care communities. Related research in that specific field included Welbourne, Blanchard and Boughton (2009) who explored SOVC within online health communities for women dealing with infertility issues. They found that members with a higher sense of SOVC experienced less detrimental effects of stress hence concluding that "SOVC may be an important component of the positive health outcomes in online health groups" (p. 137). Similarly, Obst and Stafurik (2010) explored the existence and role of SOC within a disability health forum and found that "online social support and sense of community did exist between members of these sites and was associated with individual well-being” (p. 529). Both studies explored dimensions of SOC/ SOVC using a quantitative approach and were more concerned about the impact of SOC/SOVC on health outcomes.

This study's aim was to contribute to this emerging body of research relating to SOC within specific online health care communities. A working definition of an online community was proposed for the purpose of this study based on the definitions postulated by Porter (2004) 
and Blanchard (2007) as follows: an online community is a collective of stakeholders with a shared sense of community interacting via an online platform. This working definition laid emphasis on the fact that an online group can only be considered as a community if there is a form of SOC identified within that community. The sense of community elements as originally defined by McMillan and Chavis (1986) were adopted as the conceptual frame for this study given the latest conclusions of Abfalter et al. (2012).

\section{Methods}

A social constructionist approach similar to Blanchard and Markus (2004) was adopted for this investigation given the approach of immersing within the cultural and social context in which meanings were constructed (Denzin and Lincoln 2003). Data was mined from unstructured qualitative interviews conducted with eight key informants who considered themselves as active members of the charity's online forum and who voluntarily shared their experiences on this platform. Details of participant profile and contact times are provided in the table below.

Table 1: Profile of participants and estimated contact times

\begin{tabular}{|l|l|l|l|l|l|}
\hline $\begin{array}{l}\text { Identity } \\
\text { code }\end{array}$ & Region & $\begin{array}{l}\text { Age } \\
\text { range }\end{array}$ & $\begin{array}{l}\text { Interview } \\
\text { method }\end{array}$ & $\begin{array}{l}\text { Approximate } \\
\text { contact time }\end{array}$ & $\begin{array}{l}\text { Estimated } \\
\text { Recorded time }\end{array}$ \\
\hline $\mathrm{H}$ & Midlands & $60 \mathrm{~s}$ & Video Skype & $1 \mathrm{hr} 10 \mathrm{mins}$ & $1 \mathrm{hr}$ \\
\hline $\mathrm{M}$ & Midlands & $40 \mathrm{~s}$ & Video Skype & $1 \mathrm{hr} 05 \mathrm{mins}$ & $1 \mathrm{hr}$ \\
\hline $\mathrm{O}$ & London & $50 \mathrm{~s}$ & Face-to-face & $1 \mathrm{hr} 20 \mathrm{mins}$ & $1 \mathrm{hr} 05 \mathrm{mins}$ \\
\hline $\mathrm{R}$ & South & $50 \mathrm{~s}$ & Phone & $1 \mathrm{hr} 30 \mathrm{mins}$ & $1 \mathrm{hr} 18 \mathrm{mins}$ \\
\hline $\mathrm{S}$ & Midlands & $40 \mathrm{~s}$ & Face-to-face & $2 \mathrm{hr} 20 \mathrm{mins}$ & $2 \mathrm{hr} 11 \mathrm{mins}$ \\
\hline $\mathrm{T}$ & South & $50 \mathrm{~s}$ & Phone & $1 \mathrm{hr} 40 \mathrm{mins}$ & $1 \mathrm{hr} 30 \mathrm{mins}$ \\
\hline $\mathrm{U}$ & Cornwall & $50 \mathrm{~s}$ & Phone & $1 \mathrm{hr} 45 \mathrm{mins}$ & $1 \mathrm{hr} 36 \mathrm{mins}$ \\
\hline $\mathrm{V}$ & Scotland & $60 \mathrm{~s}$ & Video Skype & $1 \mathrm{hrs} 25 \mathrm{mins}$ & $1 \mathrm{hr} 16 \mathrm{mins}$ \\
\hline
\end{tabular}


A thematic analysis following the procedures of Braun and Clarke (2006) was carried out using the assistance of NVivo 10 software. All interviews were transcribed and coded using the software's structure of parent and child nodes. Statements that related to the key elements of SOC identified by McMillan and Chavis (1986) were mined and analysed following a similar strategy adopted by Reich (2010).

\section{Findings}

The thematic analysis resulted in three key themes taken verbatim from the raw data as follows: (1) We call ourselves the family (2) They haven't got time for the little people (3) It's an absolute lifeline for some people.

\subsection{We call ourselves the family}

The charitable organisation operates at a national level with physical branches spread in different parts of the country. However, there seem to be a lack of interest by some members to attend the physical face-to-face meetings in those branches. As expressed by one participant, the online forum is considered as a virtual branch for many users:

It is like a virtual branch, so to speak. And again, I guess the thing about that sort of thing, some people do want face to face and I know [Anonymised] and branches, from what I have read, do lots of things like fundraising and so on which is absolutely brilliant and vital. But if [Anonymised] valued the forum as if it was an online branch, it actually costs them little more than they're already doing, to do what they're already doing but better and more professionally. (Participant R). 
When prompted about how they perceived the physical branches, the main responses were related to the age of the members attending those meetings:

I've never joined a branch. I suspect it's full of old people who are probably my age but I don't know. That's a bit of a judgement call, isn't it? (Participant H)

What perception do I have? Probably old people - maybe a bit older than me and probably sitting around, drinking cups of tea, maybe having talks which I wouldn't find interesting. (Participant V)

Interestingly, there is no mention about the age of members on the online platform since that seem to be irrelevant given the non face-to-face interaction. The main insight here is that there are people who identify themselves more with the online forum which they consider as a sort of virtual branch where there is more opportunities to meet like-minded individuals rather than being constrained to membership in a particular geographically-based branch. While age does not seem to be an issue on online platforms, there was mention about the online community being too female-dominated. Some participants mentioned that this could have an impact on men wishing to be part of the online community:

... and it's not very good with men. We don't get many men. We don't get very many men. I mean, there are more women than men have arthritis but men tend to deal with it in a different way. Women will be very, “Oh, I'm feeling very weepy. Need a hug." Whereas men can be quite sharp and abrupt and this sort of thing and when they get too much like that, they just ban them. (Participant H)

Participant $\mathrm{H}$ here mentioned how some men were expressing themselves differently on the forum and got banned. This issue will be discussed in more detail in the following section on power and influence, but it seems that one factor that could prevent males from developing a 
sense of belonging and identification to the online is the common mode of expression agreed by a female dominated community. While some have been banned because of their deviant ways of expression, some have preferred to leave:

Men have left - and good men have left. They do come but they don't come as much as women do. They don't come in the first place. I don't know. I would think that if there were more men about, more men might come but they don't seem to stay the same way women do. (Participant H)

I think also the forum tends to be more female than male. Whether women are more affected by arthritis, I'm not $100 \%$ sure. With the inflammatory types, possibly, but over all, if you take into account the osteoarthritis, it's probably both. But the forum is largely female. (Participant S)

However despite the issues around gender, there is a general feeling of safety within the online forum. People join in because they know they will be within a space where there are people like them who understand their condition. This is specifically important in the case of arthritis which is can be an invisible form of disability:

Safety I suppose. People can go there and know that they're not going to feel different. I can't explain it. It's like when I joined. I felt, as I say, it felt like a home because I didn't feel different when I went there. I didn't feel weird, if you like. I felt - it's hard to say. It just felt safe. When I go out in the street or something, when we park in the blue disabled space, I get old people coming and knocking on my window and saying, "You're too young to park here. (Participant M)

Another reason for feeling safe is the possibility of anonymity on the forum which is encouraged by the forum administrators. It is then up to the individual member to decide if 
they want to reveal more about themselves or to even develop friendships offline as expressed by one participant who lives physically in a remote region:

I think online, your relationship with people is quite anonymous. People choose an avatar, they choose and ID for themselves. And they don't need to - it's not encouraged that they give their full names online. People will normally give their first name perhaps. It's a very anonymous thing. You do get to know people and in fact I've developed friendships from the discussion forum. I've had people come and stay with me here who live in Cornwall...So there are possibilities of making friendships but in general, it's quite an anonymous place... (Participant V)

Since joining the forum is free with any obligations to be a member of the charity physically, there are different types of users logging in for various reasons but they might not necessarily develop a sense of belonging to the forum:

Some of those people will stay and become longer term forum members. Other people, they get their diagnosis and you don't see them again. And then you get other people who come in because they've got a particular problem now. "Has anybody ever had this happen to them?" Other people will say, "Yes, that's such and such. Go and see your doctor," or, "Don't worry about that. That's whatever." And then you don't see them again for another 6 months and then they have another problem and they come back. (Participant S)

However, there seem to be a group of members who have been using the forum as a means to develop forum there is a group of active users interacting regularly on the forum: 
I would say there are probably 20 or 30 very active members, possibly not that many, who are there all the time. But it's an online forum and it's not one of these that you go into and you find nobody has posted on there for three weeks or three months or a year or what have you. (Respondent R)

The small group of users seem to be the core of the online forum where they do not only engage regularly but they also feel a close connection with each other:

I do say it's a family. It's because you've got a caring side, you've got a fun side, and you've got a side there if you want to sob or if you want to moan. It is like a giant family. You've got the brother, the sister, the mother... We call ourselves the family, sometimes. (Respondent M).

\subsection{They haven't got time for the little people}

The forum seems to have developed organically through the active participation of a core group of members. Participant $\mathrm{R}$ who considers himself as a long-time and active contributor to the forum argued that the forum has developed quite organically through the involvement of the core members with minimal intervention of the charity which has been providing the e platform. However, there is a feeling that more could have been done to involve members into the managerial aspects of the forum. There seem to be a perception that ordinary members of the forum are not valued and are not given due consideration by the charity's management:

There are people trying to communicate from the bottom but there's just this wall that you come up against as if they haven't got time for the little people. (Respondent H) 
I don't think I'm the only person that's said to you that upstairs doesn't necessarily care whether the forum survives or not. I'd be surprised if I was the only person that said that and if I am, I'm the only one that's being honest. It has to have been said. (Respondent U)

The perception that the online forum is more of a nuisance than a stakeholder group to count on is reinforced when members try to communicate to managers to provide suggestions about the forum or when members feel that there are not enough resources being devoted to the forum. There was mention of a situation where there was no web manager over a period of time which gave rise to several issues on the forum. While there is a willingness from some forum users to help in addressing issues arising on the forum, they feel that they do not have much influence and power to be involved in improving their own community:

They don't know much about the forum. They don't want to learn much about the forum from the people who are there and would - I know one or two, besides myself, have offered to say, "Look, we think it could be improved in this way." They don't really want to know, possibly because they just don't have the manpower to deal with it. That's the kindest interpretation... Arrogance and ignorance is how I'd put it. (Participant $\mathrm{H})$

The charity seemed to have adopted a top-down hierarchy approach with regards to management as explained by the following volunteer moderator:

I think while we had a stable moderating team - they're all volunteers and then a supervisor and then a web manager - you had a matrix of support there. That all 
changed when [Anonymised] went through the financial difficulties. The web manager left and the forum supervisor hasn't been present so we were left just to get on with it.

The consequences of having such a hierarchical structure is that members do not feel that they have enough influence on their community but also that in the absence of a manager, the community is at the mercy of troublemakers who would be involved in bullying members:

...there was a lot of bullying at one stage on the forum so I stopped posting on it.

Bullying and goading and then people ganging up against others. It was actually quite unpleasant and I felt they didn't deal with that terribly well. (Respondent O)

Moderators have also been victims of such troublemakers where they felt not being able to cope with members being bullied but also in some cases where they were being under attack themselves. Another issue that was raised was the lack of transparency when decisions were taken to ban individuals from the forum:

I also did hear that some people were banned and they didn't really know why they were banned so they enquired with the web manager or whoever but they either didn't get a reply back or they were told that they were banned - I don't quite know how they phrase it - but they didn't have to tell them or get into any correspondence as to the exact reasons why they were no longer welcome on the forum. So I sometimes feel that some of those people really do need the forum but because they perhaps blotted their copybook a bit, and they may have done it a few times, they haven't actually been told what they did so that they can have a discussion about it. They're not allowed to say, 
"Please let me have one more try. Give me one more chance because I really do need the forum and really find it helps me.

(Respondent T)

The main issues identified under this second theme were firstly that ordinary forum members felt that they were not valued by management and even considered as an inferior stakeholder group as compared to other physical ones. The second issue was that the top-down management structure of the forum did not allow for ordinary members to contribute to decisions regarding their own online community. The third issue was that the existence of troublemakers who took advantage of the lack of moderation. However, it was also mentioned that there could also be the perception that some members would have been treated unfairly in the absence of transparency with regards to the banning of members.

\section{It's an absolute lifeline for some people}

The online forum seems to be valued by members in a way that they perceive it as much more than a communication platform. From the discussions with participants, it was clear that there was a strong sense of support and care among each other. The common connection that most users have when they come to the forum is that their lives have been affected by arthritis and one way or the other and the main reasons for joining in at the beginning would be to seek both informational and emotional support. Some participants also pointed out that $t$ joining the forum might not an easy thing to do and some related their own days of lurking before finally deciding to join. Most people who have decided to stay in the forum would have had a very positive experience when they joined in: 
It's a great feeling. I can't tell you how wonderful it is and I know people feel that now. A new person comes in and everybody replies and that person feels the same and I think that's fabulous because that's what you want it to be for, for those new people who today, are doing what I did then. (Participant S).

However, it is to be noted that not everyone would have had a similar positive experience from joining the forum. There have been cases where some people have felt ignored on bullied so decided not to join. But for the vast majority, there is a core group who strive to provide care and support just like others have helped them when they just joined in:

I think I care for a lot of its members because I go on the forum and try to - when they come on and they're very frightened or when people have questions about also sorts of things to do with replacement joints and this sort of thing. Anything that I feel I can help with, I will help those people and I do feel that I'm caring for them.

There are people on the forum who would invest themselves in supporting others voluntarily because they felt the support when they join in and therefore they feel a sense of responsibility towards the group but also it is a form of feeling useful again in society. This is even more relevant for those people who have stopped working because of their condition.

For me, I do more of the supporting than the asking particularly because I've been at it for such a long time. That's something that I can offer and there are core groups of people that are always there on the forum and I do tend to count myself in on that. They're there quite a lot of the time and are usually there on a continual basis rather than dipping in and out and just disappearing for a while at a time. It's important for us to try to provide that support for people and I know from what people have said particularly new people to the forum - they find that kind of thing really valuable... I can't work at the moment but it makes me feel useful and as if I've got a purpose and 
that something good has come out of a very difficult situation. So I think that benefits not only the individuals who are being helped but also those doing the volunteering, as well. (Participant R)

There also seem to be an acknowledgement from members that the forum is a lifeline for many people - something that they feel the charity management do not really understand. Based on their experiences in providing voluntarily support on the forum, they feel that the forum could be the only outlet for some people to escape from isolation or from the perception of being invisible in their physical neighbourhood.

It's an absolute lifeline for some people and you can tell it's an absolute lifeline. Some people are on there morning, noon and night. They must need it. (Participant S)

It was also interesting to find out that the forum is not only perceived as being a lifeline for people seeking help and support but also for some who are providing the support as expressed by one long-time member of the forum:

That's become a real lifeline for me and I know that, through that, I'm also able to use my experience to help other people and that matters to me hugely. So the thought that that support mechanism has actually disappeared over night, that would be terribly upsetting. (Participant R)

Some members who have been active for a while on the forum have even sought for ways to develop that relationship further and the most common official route would be to apply to become a volunteer moderator on the forum:

So my relationship has changed and I don't use the forum now as a discussion forum with other members but as moderators, we support one another. We have our own 
forum online and we've formed quite a tight knit group now of moderators so we tend to support one another within the moderator network. (Respondent V)

Some members have found ways to progress in their involvement without going through the official moderator route but by adapting the platform to develop a sort of micro-community within the community. The following two examples illustrate this point:

I set up a book club and I only set it up thinking it was just going to be a couple of people who read and that. Now, we've got around 30 or 40 members and it's still growing. That book club has become - that's my little venture, really. I sort of look after it and make sure everybody's happy on there. And that's been really fun, doing that. (Respondent M).

Another interesting example is the creation of a virtual cruise ship within the online forum:

We started doing our own little virtual cruise ship and we were all given different jobs and it was just this whole virtual cruise ship. It went on for weeks and it was really funny. (Respondent M).

The positive experiences of this particular forum make it difficult for some users to even consider another online forum in case that one ceased to exist.

I'm certainly not migrating to another forum...Actually, it's my only forum. Unless the dog counts... (Participant U)

The main insights gathered under this third theme were that for many users (both seeking and giving care) this forum is very important to them and that they would not even consider migrating to another forum. Those who have been helped in the past feel a sense of moral responsibility to do the same for newcomers. Some core users also feel a deep sense of responsibility towards the forum and seem to care about its current state and its future. 


\section{Discussion}

Findings suggest that this particular online community involving people living with arthritis consisted of two types of members which could be labelled as casual members and core members. The level of SOC experienced by different members would vary with core members experiencing a strong level of SOC within the community as illustrated through the examples in Table 3. In this section, the issues around the main elements of SOC as manifested within this particular online community are discussed with suggestions on how the charity's management could take measures on strengthening SOC.

Table 3. Elements of SOC (McMillan and Chavis 1986) as perceived by core members

\begin{tabular}{|l|l|l|}
\hline \multicolumn{1}{|c|}{ Elements } & \multicolumn{1}{|c|}{ Definition } & \multicolumn{1}{|c|}{ Examples } \\
\hline Membership & $\begin{array}{l}\text { The feeling of belonging or of } \\
\text { sharing a sense of personal } \\
\text { relatedness }\end{array}$ & $\begin{array}{l}\text { I do say it's a family. It's because } \\
\text { you've got a caring side, you've } \\
\text { got a fun side, you've got a side } \\
\text { there if you want to sob or if you } \\
\text { want to moan. It is like a giant } \\
\text { family.(Participant M) }\end{array}$ \\
\hline Influence & $\begin{array}{l}\text { A sense of mattering, of } \\
\text { making a difference to the a } \\
\text { group and of the group } \\
\text { mattering to its members }\end{array}$ & $\begin{array}{l}\text { Anything that I feel I can help } \\
\text { with, I will help those people and } \\
\text { I do feel that I'm caring for them. } \\
\text { (Participant H) }\end{array}$ \\
\hline $\begin{array}{l}\text { Integration and } \\
\text { fulfilment of needs }\end{array}$ & $\begin{array}{l}\text { The feeling that members' } \\
\text { needs will be met by } \\
\text { resources received through } \\
\text { their membership in the } \\
\text { group }\end{array}$ & $\begin{array}{l}\text { It was a forum that I fairly } \\
\text { quickly got involved with and } \\
\text { found that it was very helpful } \\
\text { because I was able to share how } \\
\text { this disease was affecting me } \\
\text { without having the burden or } \\
\text { feeling that I was burdening } \\
\text { someone else with it. (Participant } \\
\text { V) }\end{array}$ \\
\hline $\begin{array}{l}\text { Shared emotional } \\
\text { connection }\end{array}$ & $\begin{array}{l}\text { The commitment and belief } \\
\text { that members have shared } \\
\text { and will share history, } \\
\text { common places, time together } \\
\text { and similar experiences }\end{array}$ & $\begin{array}{l}\text { It's a great feeling. I can't tell } \\
\text { you how wonderful it is and I } \\
\text { know people feel that now. A new } \\
\text { person comes in and everybody } \\
\text { replies and that person feels the } \\
\text { same... (Participant S) }\end{array}$ \\
\hline
\end{tabular}


McMillan and Chavis (1986) postulated that the main attributes of membership were "boundaries, emotional safety, a sense of belonging and identification, personal investment, and a common symbol system" (p. 11). Findings indicated a strong sense of membership manifested by core members of the forum. People living with arthritis found in the forum a safe place to come and share their experiences of the condition mainly because they felt that they were being listened by people who have experienced similar things. However, there was also the presence of deviant members who did not conform to the rules and who were involved in bullying or other non-conformist behaviour (McMillan and Chavis 1986). Findings also suggested that core members felt a sense of moral responsibly in providing support to other members especially the new joiners. Another core member even mentioned that she tried her best to reply to posts that were not been replied to because she would not want anyone to feel invisible. The forum also had a common symbol system in the form of house rules as well as a particular tone of language which was considered as being mainly female-orientated. In order to reinforce the element of membership, the community manager could intervene in reinforcing the males' sense of belonging by giving them a space within the forum with a different community script that would be appealing and appropriate for them (Fournier 2009). The common symbol system also needs to be reinforced and some immediate actions could involve the creation of a sub-brand for the online forum since it is considered as a virtual branch by users. Moreover, some moderators could be assigned the roles of storyteller whose aim would be to spread "the community's story throughout the group" (Fournier 2009, p. 7). Members could be encouraged to develop rituals that would be specific to their community such as welcomes or celebrating members' length of stay within the community. Gamification elements could also be used to reinforce the common symbol system as well as members' feelings of influence such as titles/badges awarded to different types of membership or level of engagement on the forum (Bista et al. 2012). 
Based on the body of research around the sociology of communities, McMillan and Chavis (1986) postulated that members tend to feel more attracted towards a community where they feel they can have an influential role. They also suggested that the more individual is given means to participate in the affairs of the community, the more they would develop a sense of ownership of community. Findings suggest that core members feel that they do have some level of influence on other members in ensuring that community norms (e.g. house rules) are being promoted and enforced. However, there was a felt perception that core members were not valued enough by management with regards to having their say in certain forum affairs such as suggestions to improving different aspects of the forum or proposing news ideas and initiatives. Given the fact that prior research has shown that "members are more attracted to a community in which they feel that they are influential" (McMillan and Chavis 1986, 12), community managers need to realise the importance of empowering core members and get them more involved in the affairs of the community. It is important that management understands the changing aspirations of core members at different stages in the life-cycle of the community (Iriberri and Leroy 2009). While some core members are happy to evolve into moderators to assist the community manager as they move from casual to core members over the years, some might be interested in other roles where they feel that can have an influential role in some way on the affairs of the community. For instance, Fournier (2009) suggested 18 critical community roles that could be created to better engage members as their needs change over time. These would likely to strengthen the bond (McMillan and Chavis 1986) of the core members and consequently SOC within that community.

Due to the nature of the health care online community, it was not surprising to find strong feelings of shared emotional connection. However, managers could consider ways to reinforce this shared emotional connection by adapting activities that are already been done for its members offline such as honouring long-standing members or contributors, creating 
important events to share emotionally, and even opportunities to experience a form of spiritual bond among members (McMillan and Chavis 1986). To further enhance integration with the forum, managing could also consider reinforcing the link between the charity brand elements (mission, values, personality, etc.) with that of the forum. It was felt that some core members tended to have a strong sense of integration and belonging towards the online forum but not towards the charity itself. Therefore it is also important to make sure that the brand identity of the charity is extended to the forum.

\section{Conclusion}

The SOC perspective adopted in analysing this online community allowed for a more focussed attention to certain dimensions that could prove useful for managers to reinforce SOC within that community. While there was evidence of SOC among core members who felt a strong sense of belonging as well as a community allowing them to fulfil both their informational and emotional needs, it was also found that there was room for improvement along all the four dimensions that constitutes SOC as conceptualised by (Macmillan and Chavis 1986). The common symbol system could be further strengthening with the active participation of members and techniques from gamification could be adapted to reinforce SOC among a wider membership. It is clear from this study that the online community needs to be valued and considered as a key stakeholder group to be consulted by the charity. There should also be a better integration of the charity brand mission and values across the online community where core members could be recruited to champion the values of the brand within the online community. Future research could also explore in more depth the role of deviant members as well as comparing the SOC feelings of core members with casual members using quantitative scales. 


\section{References}

Abfalter, Dagmar, Melanie E. Zaglia, and Julia Mueller. "Sense of virtual community: A follow up on its measurement." Computers in Human Behavior 28, no. 2 (2012): 400-404.

Bista, Sanat Kumar, Surya Nepal, Nathalie Colineau, and Cecile Paris. "Using gamification in an online community." In Collaborative Computing: Networking, Applications and Worksharing (CollaborateCom), 2012 8th International Conference on, pp. 611-618. IEEE, 2012.

Blanchard, Anita L., and M. Lynne Markus. "The experienced sense of a virtual community: Characteristics and processes." ACM Sigmis Database 35, no. 1 (2004): 64-79.

Blanchard, Anita L. "Developing a sense of virtual community measure." CyberPsychology \& Behavior 10, no. 6 (2007): 827-830.

Blanchard, Anita L. "Testing a model of sense of virtual community." Computers in Human Behavior 24, no. 5 (2008): 2107-2123.

Braun, Virginia, and Victoria Clarke. "Using thematic analysis in psychology." Qualitative research in psychology 3, no. 2 (2006): 77-101.

Chavis, D. M., K. S. Lee, and J. D. Acosta. "The sense of community (SCI) revised: The reliability and validity of the SCI-2." In 2nd international community psychology conference, Lisboa, Portugal. 2008. 
Denzin, Norman K., and Yvonna S. Lincoln. "The landscapes of qualitative research." (2003).

Doolittle, Robert J., and Donald MacDonald. "Communication and a sense of community in a metropolitan neighborhood: A factor analytic examination." Communication quarterly 26, no. 3 (1978): 2-7.

Fournier, Susan, and Lara Lee. "Getting brand communities right." Harvard business review 87, no. 4 (2009): 105-111.

Glynn, Thomas J. "Psychological sense of community: Measurement and application." Human Relations 34, no. 9 (1981): 789-818.

Iriberri, Alicia, and Gondy Leroy. "A life-cycle perspective on online community success." ACM Computing Surveys (CSUR) 41, no. 2 (2009): 11.

Johnson, Grace J., and Paul J. Ambrose. "Neo-tribes: The power and potential of online communities in health care." Communications of the ACM 49, no. 1 (2006): 107-113.

Kirk, Susan, and Linda Milnes. "An exploration of how young people and parents use online support in the context of living with cystic fibrosis." Health Expectations 19, no. 2 (2016): 309-321. 
Koh, Joon, Young-Gul Kim, and Young-Gul Kim. "Sense of virtual community: A conceptual framework and empirical validation." International Journal of Electronic Commerce 8, no. 2 (2003): 75-94.

McMillan, David W., and David M. Chavis. "Sense of community: A definition and theory." Journal of community psychology 14, no. 1 (1986): 6-23.

Obst, Patricia, and Jana Stafurik. "Online we are all able bodied: online psychological sense of community and social support found through membership of disability-specific websites promotes well-being for people living with a physical disability." Journal of Community \& Applied Social Psychology 20, no. 6 (2010): 525-531.

Porter, Constance Elise. "A typology of virtual communities: A multi-disciplinary foundation for future research." Journal of Computer-Mediated Communication 10, no. 1 (2004): 00-00. Preece, Jenny. "Sociability and usability in online communities: Determining and measuring success." Behaviour \& Information Technology 20, no. 5 (2001): 347-356.

Reich, Stephanie M. "Adolescents' sense of community on myspace and facebook: a mixedmethods approach." Journal of community psychology 38, no. 6 (2010): 688-705.

Welbourne, Jennifer L., Anita L. Blanchard, and Marla D. Boughton. "Supportive communication, sense of virtual community and health outcomes in online infertility groups." In Proceedings of the fourth international conference on Communities and technologies, pp. 31-40. ACM, 2009. 